\title{
Marble ish
}

\section{MAYA ALAM}

Syracuse University

Let's begin by considering the suffix $\sim$ ish as an architectural concept.

Amidst the chaos of the contemporary world, many architects seek the certainty of absolutes. Yet, everything about the contemporary world tells us that it is not governed by certitude. Instead, ours is a world where everything exists in a radical state of the 'in-between,' where nothing, not even architecture, has a fixed, certain, or absolute identity. In such a world, architects must adjust or risk becoming irrelevant.

As an adjectival form, ish suggests identity (green ish, American ish), while at the same time mitigating precisely against identity.

ish is a subversive means of both supporting and undermining identity, of calling attention to a feature or characteristic of an identity that is precisely not that identity.

Green ish is not green.

"Ishness" simultaneously names and calls into question identity proper, and, in so doing, gives us a way to continue to make architecture in a world where the material certainties of wood, steel, glass and concrete have given way to the immaterial uncertainties of the mediated environments that we all inhabit. In architecture, ish emboldens the roguish and disobedient among us who refuse the absolute and embrace the 'in-between.'

The images of the Marble Room are based on a LiDAR 3D scanner project from 2016.

While this particular project aimed to create a digital, threedimensional documentation, survey and archive of the School of Architecture, Marble ish focuses on the exhibition as site for visual activism and investigation.

Through a variety of digital operations the installation is transformed into an active landscape which questions the scanner's ability to accurately document - and thus produce - a definitive 'picturing' of the real.

As such, the installation allows us to speculate on the potential of many new depictions of the real all brought together in a single, mediated space. 


\section{Marble -ish}

Let's begin by considering the suffix $-i s h$ as an architectural concept.

Amidst the chaos of the contemporary world, many architects seek the certainty of absolutes. Yet, everything about the contemporary world tells us that it is not governed by certitude. Instead, ours is a world where everything exists in a radical state of the 'in-between,' where nothing, not even architecture, has a fixed, certain, or absolute identity. In such a world, architects must adjust or risk becoming irrelevant. As an adjectival form, - ish suggests identity (green - ish, American $-i s h)$, while at the same time mitigating precisely against identity.
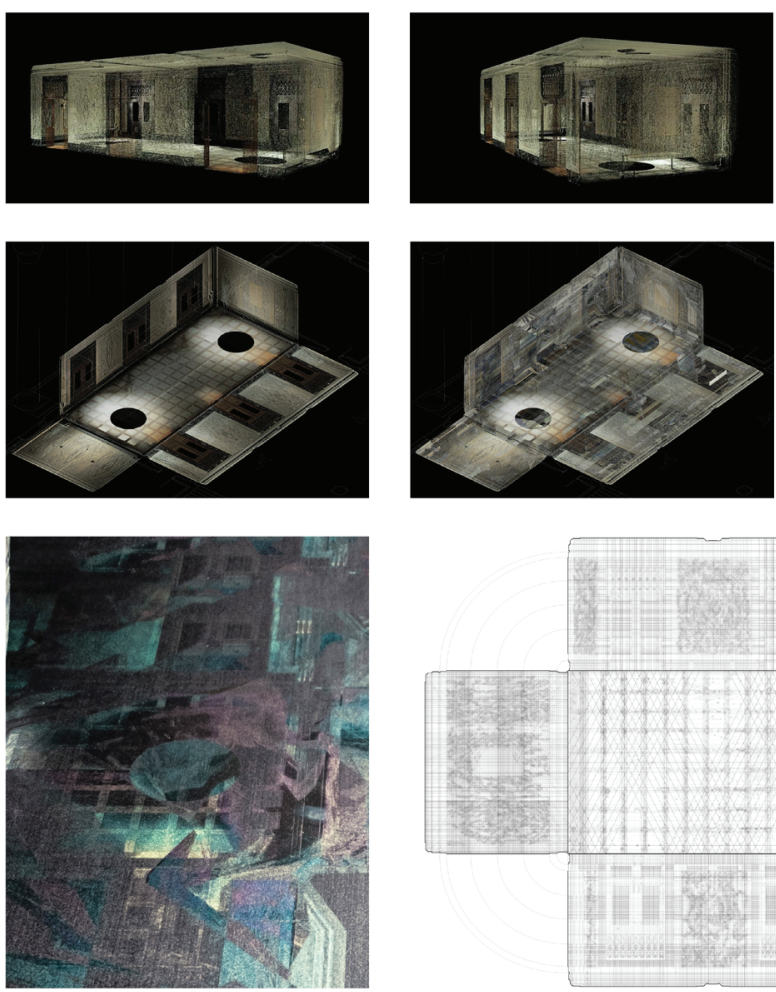

$\sim$ ish is a subversive means of both supporting and undermining identity, of calling attention to a feature or characteristic of an identity that is precisely not that identity.

Green - ish is not green.

"Ishness" simultaneously names and call into question identity proper, and, in so doing, gives us a way to continue to make architecture in a world where the
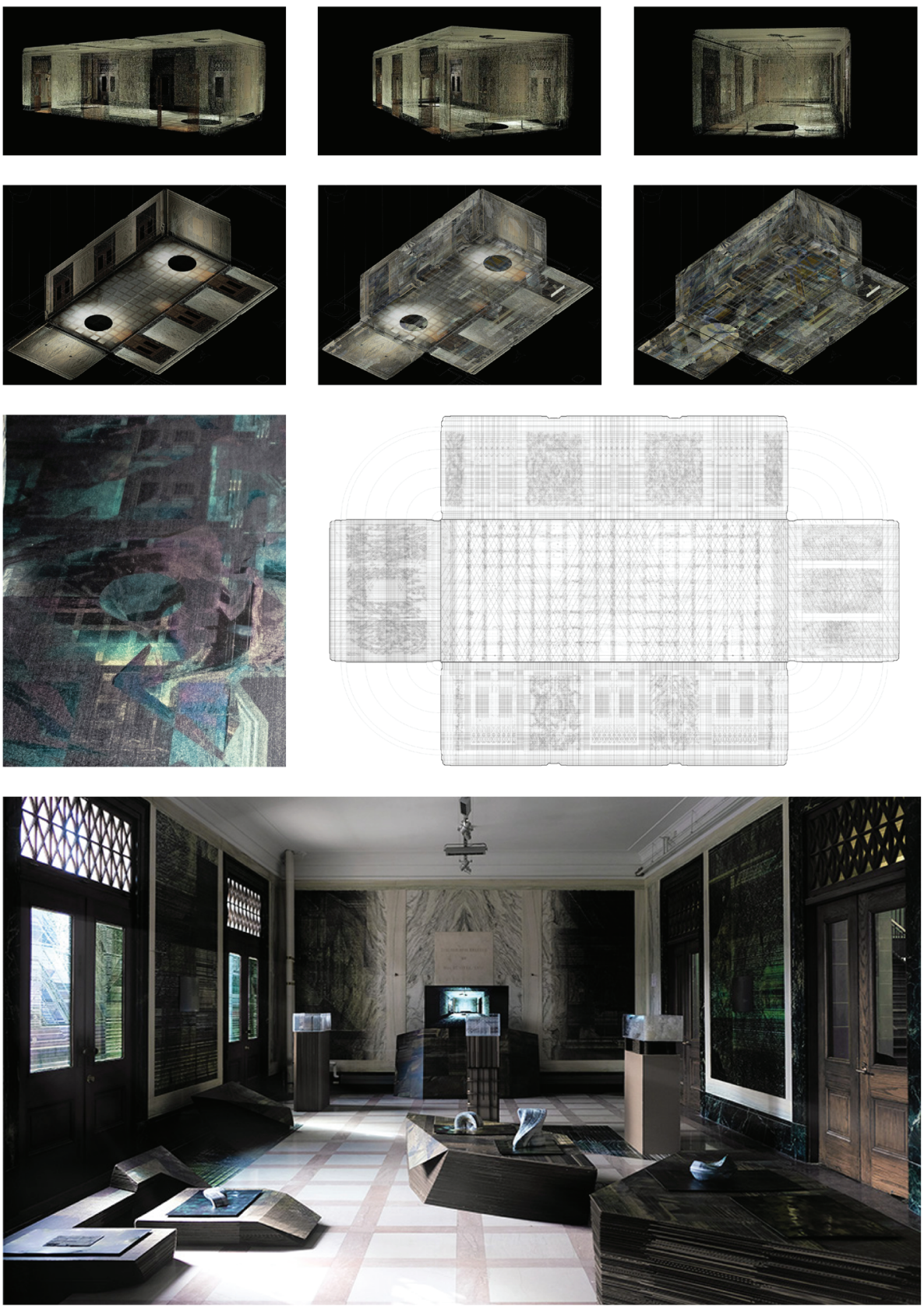
concrete have given way to the immaterial

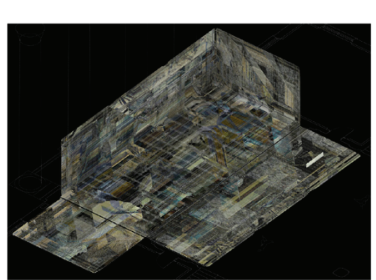

material certainties of wood, steel, glass and uncertainties of the mediated environment that we all inhabit. In architecture, - ish emboldens the roguish and disobedient among us who refuse the absolute and

The images of the Marble Room are based

While this particular project aimed to create a digital, three-dimensional documentation, survey and archive of the School of Architecture, Marble - ish focuses on the exhibition as site for visual activism and investigation.

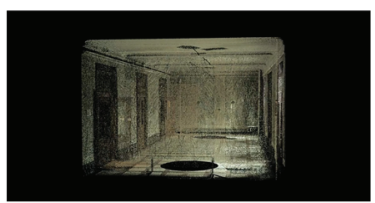

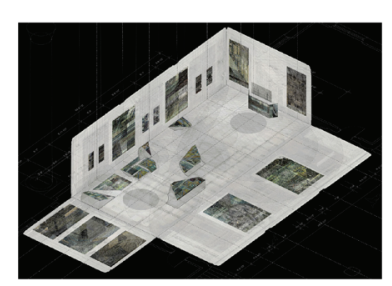

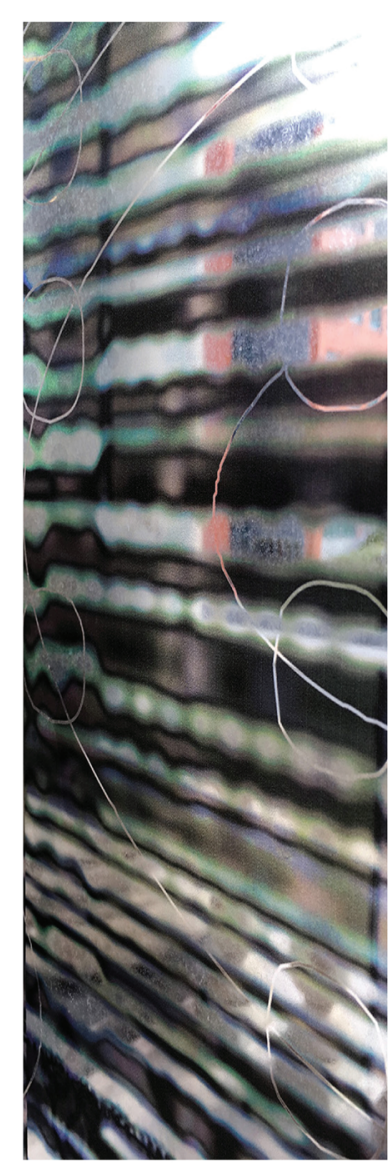

Through a variety of digital operations the installation is transformed into an active landscape which questions the scanner's ability to accurately document - and thus produce - a definitive 'picturing' of the real.

As such, the installation allows us to speculate on the potential of many new depictions of the real all brought together in a single, mediated space.

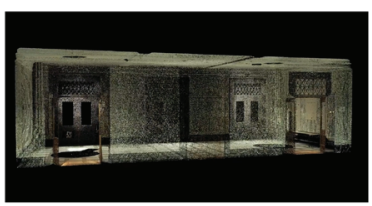

